\section{Significance of Marginally Elevated Calcitonin Levels in Micromedullary Thyroid Cancer}

\section{TO THE EDITORS:}

Recently, Pillarisetty et al. reported elevated postoperative calcitonin levels for zero of nine patients with sporadic medullary thyroid cancer $\leq 5 \mathrm{~mm}$ and for four of nine patients with 5- to 10-mm large sporadic medullary thyroid cancer $\left(6.2,14,77\right.$, and $644 \mathrm{pg} / \mathrm{mL}$, respectively). ${ }^{1}$ No follow-up data were provided for the first two patients. The third patient revealed a slight decrease in her calcitonin level after 3 years; and the fourth patient had two mildly enlarged, nonpalpable, ipsilateral level V nodes that were stable for more than 4 years. In the authors' view, "only the latter two patients appeared to have clinically undetectable persistence of medullary thyroid cancer." This statement raises important issues.

Calcitonin, correlating very well with tumor burden, is a sensitive biomarker of medullary thyroid cancer. ${ }^{2}$ In the absence of distant metastases, it is common practice to judge the adequacy of surgery for medullary thyroid cancer by the postoperative normalization of calcitonin levels ("biochemical cure"). As a matter of principle, all four patients with increased basal calcitonin levels, failing to convert to normal, must be considered as having minimal disease. Because they grow slowly, these small tumor deposits are unlikely to visualize within 3 to 4 years of follow-up but can cause problems long-term through extranodal growth. ${ }^{3}$

In patients with recurrent and persistent medullary thyroid cancer, and even more so in minimal disease, cervical ultrasound often is of little avail, yielding false-negative findings in $44 \%(27 / 61)$ to $49 \%$ (19/39) of patients. ${ }^{4}$ With postoperative calcitonin levels increased, the issue of compartment-oriented surgery to achieve local control in the neck always comes up unless the central (level VI) and lateral neck compartments (levels II-V) have been cleared bilaterally in a systematic fashion. To make this determination, knowing the number of involved nodes relative to those removed is crucial. These histopathologic data are not only an excellent indicator of the extent of lymph node dissection but also signify the risk of lateral neck involvement: with a single positive central neck node, the lateral neck compartment is involved in $71 \%$ ipsilaterally and $33 \%$ contralaterally. ${ }^{5}$

We wonder whether the authors could kindly supply the reader with this important histopathologic information to enable assessment of the extent of lymph node dissection in these four patients with residual disease. Some of them, particularly those with marginally elevated calcitonin levels, may still be curable through the systematic use of the technique of bilateral compartment-oriented surgery.

\section{Andreas Machens, MD, and Henning Dralle, MD}

Department of General, Visceral and Vascular Surgery, Martin Luther University, Halle, Germany

e-mail: AndreasMachens@aol.com

Published Online: 28 July 2009

(C) Society of Surgical Oncology 2009

\section{REFERENCES}

1. Pillarissetty VG, Katz SC, Ghossein RA, Tuttle M, Shaha AR. Micromedullary thyroid cancer: how micro is truly micro? Ann Surg Oncol. DOI 10.1245/s10434-009-0595; e-pub ahead of print 1 July 2009.

2. Machens A, Schneyer U, Holzhausen HJ, Dralle H. Prospects of remission in medullary thyroid carcinoma according to basal calcitonin levels. J Clin Endocrinol Metab. 2005;90:2029-34.

3. Machens A, Hinze R, Lautenschläger C, Thomusch O, Dralle H. Thyroid carcinoma invading the cervicovisceral axis: routes of invasion and clinical implications. Surgery. 2001;129:23-8.

4. Kouvaraki MA, Shapiro SE, Fornage BD, Edeiken-Monro BS, Sherman SI, Vassilopoulou-Sellin R, Lee JE, Evans DB. Role of preoperative ultrasonography in the surgical management of patients with thyroid cancer. Surgery. 2003;134:946-55.

5. Machens A, Hauptmann S, Dralle H. Prediction of lateral lymph node metastases in medullary thyroid cancer. $\mathrm{Br} J$ Surg. 2008;95:586-91. 